\title{
Expression of Sympathetic Activity in College Students with Hypertension
}

\author{
Ling $\mathrm{Li}^{1,2,3}$, Haiying Zhao ${ }^{1,2,3 *}$, Hao Wang ${ }^{1,2,3}$, Xiaoyi $\mathrm{Ji}^{3}$, Yaru $\mathrm{Li}^{3}$, Chunli Zhang ${ }^{4}$, Xinyu Wang ${ }^{4}$ \\ and Ling Jiang ${ }^{1,2,3}$ \\ ${ }^{1}$ Department of Hypertension, Henan Provincial People's Hospital, China \\ ${ }^{2}$ Henan key Laboratory for Hypertension Study, Zhengzhou, China \\ ${ }^{3}$ Henan University People's Hospital,Zhengzhou, China \\ ${ }^{4}$ Zhengzhou YiHe Hospital, Zhengzhou, China
}

*Corresponding author: Haiying Zhao, Department of Hypertension, Henan Provincial People's Hospital, No.7, Weiwu Road, Jinshui District, Zhengzhou 450003, China.

To Cite This Article: Ling Li, Haiying Zhao, Hao Wang, Xiaoyi Ji, Yaru Li, Expression of Sympathetic Activity in College Students with Hypertension. Am J Biomed Sci \& Res. 2021 - 11(6). AJBSR.MS.ID.001696. DOI: 10.34297/AJBSR.2021.11.001696.

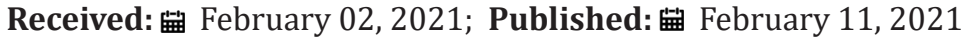

\begin{abstract}
To explore the expression of sympathetic activity in college students with hypertension. Methods: A random and cluster sampling was used to recruit subjects; 5185 students were collected in this investigation from 3 universities in Zhengzhou from March to December 2018. Stratified sampling in R language was used to select 184 from non-hypertension students, 201 from hypertension students. Serum dopamine (DA), norepinephrine (NE), epinephrine (E), plasma renin activity (PRA), angiotensin II (AngII), aldosterone (ALD), urine sodium and resting heart rate (HR) were tested for 385(184+201) students, using independent samples test to compare the difference between two groups, Spearman rank correlation coefficient to assess the correlation of physicochemical parameters and hypertension, and multiple linear regression to analyze the risk factors of hypertension. 385 students were divided into two groups---overweight group and non-overweight group---according to the BMI. Compare the differences of prevalence of hypertension with physicochemical parameters between two groups. Results: There were statistical difference between two groups in PRA, E, AngII, urinary sodium and HR ( $\mathrm{P}=0.005,0.000,0.013,0.04,<0.001)$. Spearman rank correlation coefficient showed that $\mathrm{E}$ (SBP $\mathrm{r}=0.428$, $\mathrm{P}=0.000$; DBP $r=0.388, \mathrm{P}=0.000$ ) and $\mathrm{HR}(\mathrm{SBP} r=0.282, \mathrm{P}=0.000$; DBP $\mathrm{r}=0.318, \mathrm{P}=0.000$ ) had positive correlations with $\mathrm{BP}$, while $\mathrm{PRA}$ had a negative correlation with BP (SBP r=-0.147, $\mathrm{P}=0.013$; DBP $\mathrm{r}=-0.156, \mathrm{P}=0.008$ ). Logistic regression showed $\mathrm{E}$ was an independent risk factor of hypertension (OR=1.123, 95\%CI: 1.008-1.252, P<0.05). DA, NE, E, PRA, AngII, ALD, sodium urine and HR showed no significant difference between overweight and non-overweight group $(\mathrm{P}>0.05)$. Conclusion: Excessive sympathetic activation is the independent risk factor of hypertension in college students.
\end{abstract}

Keywords: College students, Hypertension, Sympathetic activity, Renin-angiotensin-aldosterone system (RAAS), Sodium water retention

\section{Introduction}

Hypertension is the most common chronic non-communicable disease. The prevalence of hypertension in young people is gradually increasing. According to the 2012-2015 national survey, the prevalence of hypertension among 18-24 years old is $4 \%$ [1]. Increased sympathetic activity, sodium-water retention and hyperactivity of renin-angiotensin-aldosterone system (RAAS) had been confirmed the main mechanisms leading to essential hypertension (EH) [2]. In this study, the sympathetic active, urinary sodium and RAAS were detected in college students, and the correlation between these factors and blood pressure were compared, to provide evidences for the prevention and treatment of hypertension in college students.

\section{Subject and Methods}

\section{Subjects}

A total of 5185 students were randomly selected via cluster sampling from three universities in Zhengzhou, Henan Province, China, whose BP, height and weight were measured. Stratified 
sampling in R language was used to select 406 subjects randomly from 5185 students, including 203 non-hypertensive subjects and 203 hypertensive subjects. And then we excluded incomplete data and subjects who did not meet the selection criteria. Finally, 385 subjects were included, including 184 non-hypertensive subjects and 201 hypertensive subjects. According to the 2018 Chinese Guideline for Hypertension [3], students were divided into nonhypertension group (NHTN) and hypertension group (HTN). The individuals were divided into four categories according to BMI: below $18.5 \mathrm{~kg} / \mathrm{m} 2$ (underweight); $18.5-23.9 \mathrm{~kg} / \mathrm{m} 2$ (normal); 24.0-27.9 kg/m2 (overweight); $28.0 \mathrm{~kg} / \mathrm{m} 2$ and above (obesity) [4]. BP was measured by a BP monitor (Omron HBP-1300, Kyoto, Japan). Height and weight were measured twice successively using a folding portable smart internet height and weight scale (SH-600G, Zhengzhou Shanghe Electronic Technology Co., Ltd. Zhengzhou, China). Exclusion criteria: 1) severe liver or kidney disease (glutamic oxaloacetic transaminase-GOT 2 times elevated, serum creatinine> 104umol/L);2) oral contraceptives use, pregnancy plan or lactation; 3) secondary hypertension and antihypertensive drugs use;4) patients with a diagnosis of depression and anxiety disorders;5)the researchers determined that they were not suitable for enrollment. Our study had been approved by the Ethics Committee of Henan Provincial People's Hospital. All participants were well informed and agreed to sign written informed consent forms.

\section{Methods}

Trained clinical staff conducted measurements of the participants' height, weight and BP. Fasting venous blood was collected at 9:30 am-10am in the hospital, and the subjects were kept in a non-recumbent position for 2 hours after getting up in the morning to detect DA, NE, E, PRA, AngII and ALD. Leave urine in the morning to test for sodium and take a 15-minute rest after venous blood collection and lie down for the ECG detection to collect HR. DA, $\mathrm{NE}$, E were determined using Thermo full-wavelength microplate reader manufactured by Labor Diagnostica Nord GmbH, Nordhorn, Germany, and the test range were as follows: $162-33333 \mathrm{pg} / \mathrm{ml}$ for $\mathrm{E}, 93-33333 \mathrm{pg} / \mathrm{ml}$ for $\mathrm{NE}$, and $18-6667 \mathrm{pg} / \mathrm{ml}$ for E. AngII, ALD were determined using EIA commercial kit manufactured by Shenzhen New Industry, whose linearity range was $0.4-24 \mathrm{ng} / \mathrm{ml}$.
The intra-assay coefficient of variation (CV) was $\leq 10 \%$ for Ang I and $\leq 10 \%$ for Ang II. The inter-assay CV was $\leq 15 \%$ for Ang I and $\leq 15$ $\%$ for Ang II, according to the manufacturer's information. DRC was determined using commercial kit manufactured by Autobio Limited Company, Zhengzhou, He'nan, China, whose linearity range was $4.0-500.0 \mathrm{ng} / \mathrm{ml}$. The intra-assay coefficient of variation (CV) was $\leq 2.55 \%$ and the inter-assay CV was $5.97 \%$. ALD was determined using liquid chromatography-tandem mass spectrometry LC-MS/ MS supplied from SCIEX Triple Quad 4500MD LC-MS/MS system. Urine sodium was tested by ADVIA2400 Chemistry System which uses o-cresol phthaloline Ketone colorimetric method.

\section{Statistical analysis}

SPSS 22.0 software (IBM SPSS Statistics V22.0.0) was used for analysis. Normally distributed data was expressed as the mean $\pm \mathrm{SD}$. Independent $\mathrm{T}$ test was used when comparing two groups of normally distributed data. Mann-Whitney $U$ test in the non-parametric test was used for non-normally distributed data which was expressed as the median. The chi-square test was used to compare the inter-group rates. Spearman analysis was used to test the correlation between the two variables. Logistic regression was used for multivariate analysis. A two-tailed $\mathrm{P}$ value $<0.05$ was considered that there were statistic differences.

\section{Results}

\section{$\mathrm{BP}$ and $\mathrm{BMI}$ distributions}

$723(13.9 \%)$ Of the 5185 students had hypertension. There were 590 students with systolic hypertension, 36 patients with diastolic hypertension, and 97 patients with double-stage hypertension ( $\mathrm{SBP} \geq 140$ and $\mathrm{DBP} \geq 90 \mathrm{mmHg}$ ). The detection rates were $11.4 \%, 0.7 \%$ and $1.9 \%$, respectively. Of the 5185 participants, 954 cases were underweight, 3,474 cases were normal, 560 cases were overweight and 197 cases were obesity. The proportions were $18.4 \%, 67 \%, 10.8 \%$, and $3.8 \%$, respectively.

\section{Comparison of parameters between NHTN and HTN}

Except for differences SBP, DBP, AngII, Urine sodium, and HR between the two groups, there were no significant differences in other parameters, as shown in (table 1).

Table 1: Comparison of parameters between NHTN and HTN.

\begin{tabular}{|c|c|c|c|c|c|c|c|c|c|c|}
\hline & age & $\begin{array}{c}\text { male } \\
(\%)\end{array}$ & SBP (mmHg) & $\begin{array}{c}\text { DBP } \\
(\mathrm{mmHg})\end{array}$ & $\begin{array}{l}\text { PRA (ng/ } \\
\mathrm{ml} / \mathrm{h} \text { ) }\end{array}$ & $\begin{array}{c}\text { AngII } \\
(\mathrm{pg} / \mathrm{ml})\end{array}$ & $\begin{array}{l}\text { ALD (pg/ } \\
\text { ml) }\end{array}$ & $\begin{array}{l}\text { Urine Sodium } \\
\text { (mmol/L) }\end{array}$ & $\begin{array}{c}\text { HR } \\
\text { (Times/ } \\
\text { min) }\end{array}$ & $\begin{array}{c}\text { DRC } \\
\text { (ng/ml) }\end{array}$ \\
\hline NHTN $(n=184)$ & $20.4 \pm 2.2$ & $84-45.7$ & $120.5 \pm 11.9$ & $69.5 \pm 8.4$ & $2.1(1-3.9)$ & $\begin{array}{c}71.9 \\
(61.2-88.0)\end{array}$ & $\begin{array}{c}36.3 \\
(22.35- \\
62.1)\end{array}$ & $\begin{array}{c}123.5 \\
(83.5-172.0)\end{array}$ & $77(70-86)$ & $\begin{array}{c}20.2 \\
(15.0-29.5)\end{array}$ \\
\hline HTN $(n=201)$ & $20.2 \pm 1.5$ & $54-53.5$ & $152.4 \pm 11.2$ & $83.8 \pm 10.0$ & $1.1(0.6-3.3)$ & $\begin{array}{c}79.1 \\
(65.5-02.1)\end{array}$ & $\begin{array}{c}34 \\
(23.2- \\
57.0)\end{array}$ & $\begin{array}{c}145 \\
(104.0-90.0)\end{array}$ & $\begin{array}{c}85.0 \\
(75.0- \\
100.0)\end{array}$ & $\begin{array}{c}21.2 \\
(14.1-26.3)\end{array}$ \\
\hline
\end{tabular}




\begin{tabular}{|c|c|c|c|c|c|c|c|c|c|c|}
\hline $\mathbf{T} / \mathbf{c}^{2}$ & 1.202 & -1.262 & -22.204 & -12.87 & -2.824 & -2.474 & -0.407 & -2.049 & -3.985 & -0.317 \\
\hline $\mathbf{p}$-value & 0.23 & 0.208 & $<0.001$ & $<0.001$ & 0.005 & 0.013 & 0.684 & 0.04 & $<0.001$ & 0.751 \\
\hline
\end{tabular}

Note: NHTN, non-hypertension; HTN, hypertension; HR, resting heart rate; urine Na+, urine sodium; PRA, plasma renin activity; Angll, angiotensin II; ALD, aldosterone; DRC, direct renin concentration.

\section{Comparison of Catecholamines (DA, NE and E) between the two groups}

The differences in DA and E between the two groups were statistically significant, as shown in (table 2).

Table 2: Comparison of DA, NE and $E$ between the two groups.

\begin{tabular}{|c|c|c|c|c|}
\hline & $\mathbf{D A}(\mathbf{p g} / \mathbf{m l})$ & $\mathbf{N E}(\mathbf{p g} / \mathbf{m l})$ & $\mathbf{E}(\mathbf{p g} / \mathbf{m l})$ & NHTN $(\mathrm{n}=184)$ \\
\hline NHTN $(\mathrm{n}=184)$ & $84.79(60.265-108.807)$ & $65.786(48.753-101.414)$ & $39.978(15.861-56.943)$ & HTN $(\mathrm{n}=201)$ \\
\hline HTN $(\mathrm{n}=201)$ & $82.504(68.315-143.432)$ & $63.979(51.745-96.351)$ & $65.789(36.621-85.514)$ & $\mathrm{T} / \mathrm{Z} / \chi^{3}$ \\
\hline T/Z/ $\chi^{2}$ & -1.143 & -0.102 & -3.659 & $P$ value \\
\hline P value & 0.253 & 0.919 & $<0.001$ & \\
\hline
\end{tabular}

Note: NHTN, non-hypertension; HTN, hypertension; DA, dopamine; NE, norepinephrine; E, epinephrine Table 3: Correlation analysis of various parameters and BP.

\begin{tabular}{|c|c|c|c|c|c|c|c|c|c|c|}
\hline & & DA & NE & $\mathbf{E}$ & PRA & AngII & ALD & Urine sodium & HR & DRC \\
\hline \multirow{2}{*}{ SBP } & $\mathrm{r}$ & 0.094 & -0.001 & 0.428 & -0.147 & -0.027 & -0.077 & 0.077, & \multirow{2}{*}{$0.282,0.000$} & \multirow{2}{*}{$-0.079,0.185$} \\
\hline & $\mathrm{p}$ & 0.428 & 0.996 & 0 & 0.013 & 0.651 & 0.246 & 0.199 & & \\
\hline \multirow{2}{*}{ DBP } & $\mathrm{r}$ & 0.063 & 0.163 & 0.388 & -0.156 & -0.008 & -0.068 & 0.086 & \multirow{2}{*}{$0.318,0.000$} & \multirow{2}{*}{$-0.109,0.065$} \\
\hline & $\mathrm{p}$ & 0.595 & 0.303 & 0 & 0.008 & 0.89 & 0.309 & 0.146 & & \\
\hline
\end{tabular}

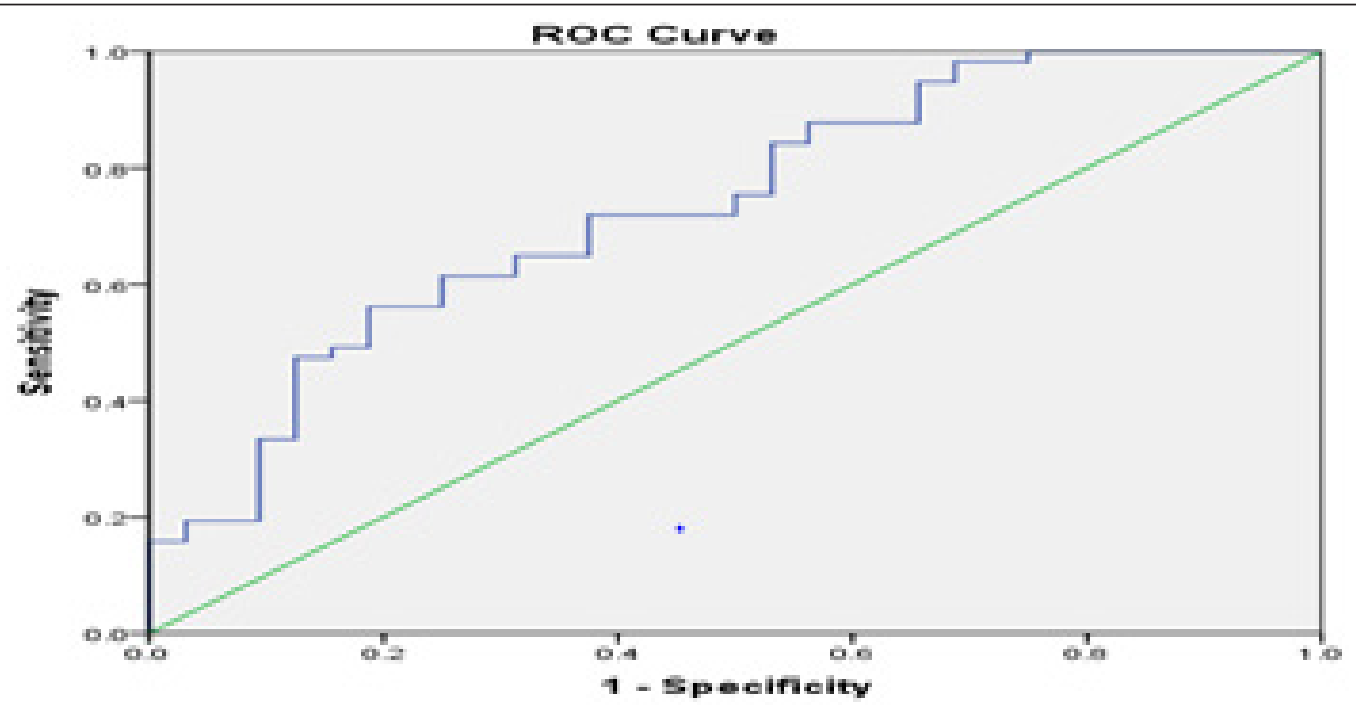

Figure 1: AUC: $0.375(95 \% \mathrm{Cl}$ : 0.62- $0.843, \mathrm{P}<0.001)$.

\section{Multivariate logistic regression analysis}

Hypertension (yes/no) was considered as dependent variable, and blood DA, E, Ang II , urinary sodium and HR were(yes/no) were considered as independent variables; A logistic regression analysis was performed and obtained results shown in (table 4). E was an independent risk factor for hypertension, and other parameters failed the test (figure 1).

\section{Comparison of parameters between non-overweight and overweight}

There was no statistically significant difference in each parameter between the two groups, as shown in (table 5,6). 
Table 4: Multivariate Logistic Regression Analysis.

\begin{tabular}{|c|c|c|c|c|c|c|}
\hline & B & SE & Wald & p -value & OR & 95\%CI \\
\hline $\mathrm{E}$ & 0.031 & 0.009 & 10.841 & 0.001 & 1.032 & $(1.013-1.051)$ \\
\hline constant & -1.052 & 0.512 & 4.22 & 0.04 & 0.349 & \\
\hline
\end{tabular}

Note: $\mathrm{Cl}$ : confidence interval; OR: odds ratio.

Table 5: Comparison of parameters between non-overweight and overweight.

\begin{tabular}{|c|c|c|c|c|c|c|c|c|c|}
\hline & $\mathrm{DA}(\mathrm{pg} / \mathrm{ml})$ & $\mathrm{NE}(\mathrm{pg} / \mathrm{ml})$ & $\mathrm{E}(\mathrm{pg} / \mathrm{ml})$ & $\begin{array}{l}\text { PRA (ng/ } \\
\text { ml/h) }\end{array}$ & Ang? (pg/ml) & $\begin{array}{l}\text { ALD (pg/ } \\
\text { ml) }\end{array}$ & $\begin{array}{c}\text { HR (Times / } \\
\text { MIN) }\end{array}$ & $\begin{array}{c}\text { Urine } \\
\text { sodium } \\
(\mathrm{mmol} / \mathrm{L})\end{array}$ & $\begin{array}{c}\text { DRC( ng/ } \\
\text { ml) }\end{array}$ \\
\hline $\begin{array}{c}\text { non-over- } \\
\text { weight } \\
(25-75 \% \\
\text { median) }\end{array}$ & 84.4 & 70.8 & 53.3 & 1.9 & 77.8 & 38.6 & 79 & 137 & 20.2 \\
\hline $\begin{array}{c}\text { Overweight } \\
(25-75 \% \\
\text { median) }\end{array}$ & 85.2 & 52.9 & 54.1 & 1.7 & 70.1 & 30.7 & 80.5 & 130 & 21.2 \\
\hline $\mathrm{T} / \mathrm{cC}^{2}$ & -0.395 & -1.671 & -0.911 & -1.036 & -1.669 & -1.664 & -0.859 & -0.09 & -0.317 \\
\hline p-value & 0.693 & 0.095 & 0.362 & 0.3 & 0.095 & 0.096 & 0.39 & 0.928 & 0.751 \\
\hline
\end{tabular}

Note: DA, dopamine; NE, norepinephrine; E, epinephrine; PRA, plasma renin activity; Ang II, angiotensin II, ALD, aldosterone; HR, resting heart rate; DRC, direct renin concentration.

Table 6: Correlation analysis between DA, NE, E, Angll, ALD,HR DRC and BMI.

\begin{tabular}{|c|c|c|c|c|c|c|c|c|}
\hline & DA & NE & E & PRA & Ang II & ALD & HR & DRC \\
\hline $\mathrm{r}$ & 0.017 & -0.185 & 0.265 & -0.081 & -0.094 & 0.024 & 0.072 & -0.061 \\
\hline $\mathrm{p}$-value & 0.884 & 0.24 & 0.012 & 0.177 & 0.114 & 0.691 & 0.228 & 0.301 \\
\hline
\end{tabular}

\section{Discussion}

The pathogenesis of essential hypertension are as follows:

1) Long-term high salt intake leads to sodium retention, vascular tension and cardiac output increased, and causes blood pressure elevated [4]. Besides, high-salt diet also causes secretion of endothelin increased, which elevates BP. And when cell membrane ion transport is defective [5], high sodium intake will also cause abnormal sodium ion metabolism, which causes a variety of pathological changes in physiological processes in the body that leads to hypertension [6]; 2) RAAS plays an important role in the development of hypertension. Ang II makes vasoconstriction and BP elevated next, while the sodium-volume effect produced by aldosterone is the main mechanism of long-term regulation of blood pressure by RAAS [7]. Further, RAAS promotes sympathetic nervous system activation, increases sodium retention in the kidney, participates in inflammatory response and mitochondrial energy metabolism and also other pathways leading to blood pressure elevated in different ways and different extents. [8]; 3) Over-stimulation of the sympathetic nerve causes heart rate increased, peripheral vascular contracted, peripheral resistance increased, and renal ischemia, which stimulates RAAS activity, and ultimately lead to BP elevated.

In this study, basal plasma DA, NE, E, and HR were used as indicators to evaluate sympathetic activity, while PRA, Ang II , and ALD were used as the indexes to judge the activity of RAAS. Urine sodium in the morning was used as the amount of salt intake and sodium load in the body. The results showed that DA, E, Ang II, urine sodium and HR in the HTN group were significantly higher than those in the NHTN group, which indicted that sympathetic nerve activity and Ang II increased and sodium-water retention might all participate in the occurrence of hypertension in college students. HR, plasma DA and E as the markers of sympathetic activity in this study showed significant differences between the two groups, and had correlations with both SBP and DBP. However, NE in blood circulation showed no difference between the two groups and was not correlated with blood pressure. The related study showed that more than $90 \%$ of epinephrine was released from the adrenal medulla in the blood circulation and worked with the blood flowing. Only a small amount of norepinephrine released from sympathetic nerve endings entered the circulatory system, most of which act near the release site and were transferred back into the nerve through neuronal re-uptake [9]. The reason why NE was not related to blood pressure in this study may be a small amount of NE released from the sympathetic nerve to the blood circulation, which could explain the detection of plasma NE was not as good as $\mathrm{E}$ in reflecting true sympathetic activity. Comparing PRA, Ang II, and ALD between the two groups, only Ang II was statistically higher in HTN group than that in non-hypertension group. The reason was that Ang II was more stable as a indicator of RASS activity in plasma compared with PRA and ALD [10,11]. BP correlation analysis showed that PRA was negatively correlated 
with SBP and DBP (SBP $r=-0.147, \mathrm{P}=0.013$; DBP $\mathrm{r}=-0.156, \mathrm{P}=$ 0.008). There are so many factors affecting renin and aldosterone [12]. Participants in this study did not take any drugs. However, dietary sodium and potassium significantly affected plasma renin levels and college students always ate in school restaurants, or take-out foods which has a common problem of excessive salt intake. It is considerable that the negative correlation between PRA and BP might be related to the inhibition of plasma renin activity by a high-salt diet. Given that hypertension as dependent variable, and DA, E, Ang II , urinary sodium and HR considered as independent variables, a logistic regression analysis was performed and showed that $\mathrm{E}$ was an independent risk factor for hypertension $(\mathrm{OR}=1.123$, 95\% CI : $1.008 \sim 1.252, \mathrm{P}<0.05$ ). DA, Ang II, urine sodium and HR all failed the test. Plasma epinephrine is a sensitive marker of sympathetic activity in blood circulation. The results of this study suggested that sympathetic hyperactivity played an important role in the pathogenesis of hypertension in college students. There was an significant difference between HTN and NHTN in urinary sodium $(P=0.04)$. However, there was no evidence that urinary sodium had a correlation with hypertension in this study which might because the young have stronger compensatory ability of renal function. Even if the high sodium diet was taken, kidney could promote the excretion of sodium through increasing blood flow in renal medulla $[13,14]$, so high sodium diet is not the main cause of hypertension.

The study has confirmed that the risk of hypertension is significantly higher in obese people, and relevant domestic studies have also showed that the rate of detection of hypertension in overweight and obese students was much higher than those with low BMI [15]. Framingham study showed that obesity was an important independent predictor of cardiovascular disease [16]. Studies have found that the activation of sympathetic nervous system and RASS in obese people are the main causes of hypertension $[17,18]$. while the results of this study showed that there were no statistical differences in DA, NE, E, PRA, AngII, ALD, urinary sodium and HR between overweight and non-overweight. Besides, E had a positive correlation with BMI ( $r=0.209, \mathrm{P}=0.015)$, while DA, NE, PRA, AngII, ALD, and HR has no relationship with BMI $(r=0.083,-0.027,-0.081,-0.094,0.024,0.072$, all $p>0.05)$. Further, the results of this study indicated that excessive sympathetic activation was an independent risk factor of hypertension in college students, and with the BMI increased, sympathetic activation was increasing gradually. However, there was no correlation between RASS activation and BMI. In this study, the detection rates of overweight and obesity $(10.8 \%, 3.8 \%)$ were both lower than the national average $(30.1 \%, 11.9 \%)$. Sympathetic activation is not only ascribed to BMI, but also to unhealthy lifestyle of college students, such as less sports, staying up late for a long time, lack of sleep, high employment pressure, etc. It is important to pay attention to the sympathetic activity of college students and to intervene in time to prevent the occurrence of hypertension. 24-hour urinary sodium can better reflect the body's sodium load than point urinary sodium. The lack of 24-hour urine sodium test in this study was a main disadvantage.

\section{References}

1. Wang Z,Chen Z, Zhang L, Xin W, Guang H et al. (2018) Status of Hypertension in China: Results from the China Hypertension Survey. Circulation 137(22): 2344-2356.

2. Bolivar JJ (2013) Essential hypertension: an approach to its etiology and neurogenic pathophysiology. Int J Hypertens 2013: 547809.

3. (2019) Joint Committee for Guideline Revision; 2018 Chinese Guidelines for Prevention and Treatment of Hypertension-A report of the Revision Committee of Chinese Guidelines for Prevention and Treatment of Hypertension. Geriatr Cardiol 16(3): 182-241.

4. Zhou B (2002) Coorperative Meta-Analysis Group of China Obesity Task Force. China Obesity Working Group Data Collection and Analysis Collaborative Group. Predictive values of body mass index and waist circumference to risk factors of related diseases in Chinese adult population. Zhonghua Liu, Xing Bing, Xue Za, Zhi 23(1): 5-10.

5. Wang W, Zhang W, Sun N (2011) Chinese guidelines for blood pressure measurement. ZhongHua Gao Xue Ya Za Zhi 19: 1101-1115.

6. Elijovich F, Weinberger MH, Anderson CA, Lawrence JA, Michael B, et al. (2016) Salt sensitivity of blood pressure: a scientific statement from the American Heart Association. Hypertension 68(3): e7-e46.

7. Eisele N, AlbrechtC, Mistry HD, Bernhard D, Marc B, et al. (2016) Placental expression of the angiogenic placental growth factor is stimulated by both aldosterone and simulated starvation. Placenta 40: 18-24.

8. Lin S (2016) Modern recognition of renin angiotensin system in the classification of hypertension. Chinese Journal of Hypertension 24(11): 1021-1024.

9. Graeme E, Thanh-TH, Mayumi H, K Pacak (2001) Understanding Catecholamine Metabolism as a Guide to the Biochemical Diagnosis of Pheochromocytoma. Reviews in Endocrine \& Metabolic Disorders 2(3): 297-311.

10. Michael S, Ashraf A, Zeng G, Martin W, Jacobus U, et al. (2017) Can Screening and Confirmatory Testing in the Management of Patients with Primary Aldosteronism be Improved? Horm Metab Res 49(12): 915921.

11. Martin J, Wolley, Michael S (2017) New Advances in the Diagnostic Workup of Primary Aldosteronism.Journal of the Endocrine Society 1(3): 149-161.

12. John WF, Robert MC, Franco M, Hassan MM, Martin R, et al. (2016) The Management of Primary Aldosteronism: Case Detection, Diagnosis, and Treatment: An Endocrine Society Clinical Practice Guideline.J Clin Endocrinol Metab 101(5): 1889-1916.

13. Ivy JR, Bailey MA (2014) Pressure natriuresis and the renal control of arterial blood pressure. J Physiol 592(18): 3955-3967.

14. Kabekkodu SP, Chakrabarty S, Shukla V, Vinay K, Keshav KS et al. (2015) Mitochondrial biology:from molecules to diseases. Mitochondrion 24: 93-98.

15.Zhou Y, Xiao L, Wang L (2018) Incidence of hypertension in young students. Chinese Journal of Hypertension 26(1): 51-55.

16. Vasan RS, Pencina MJ, Cobain M, Matthew SF, Ralph BD’A (2005) Estimated risks for developing obesity in the Framingham Heart Study. ANN.INTERN.MED 143(7): 473-480. 
17. Aghamohammadzadeh R, Heagerty AM (2012) Obesity-related hypertension: epidemiology, pathophysiology, treatments and the contribution of perivascular adipose tissue. Ann Med 44(Suppl 1): S74-S84.
18. Monica TJ, Schütten, Alfons JHM, Houben, Peter W, et al. (2017) The Link Between Adipose Tissue Renin-Angiotensin-Aldosterone System Signaling and Obesity-Associated Hypertension. PHYSIOLOGY 32(3): 197-209. 